\title{
49. HEAT-FLOW MEASUREMENTS AT HOLE 646A ${ }^{1}$
}

\author{
K. E. Louden, ${ }^{2}$ K. A. Dadey, ${ }^{3}$ and S. P. Srivastava ${ }^{4}$
}

\begin{abstract}
Three downhole temperature measurements were taken at Hole 646A using the Woods Hole Oceanographic Institution's (WHOI) Hydraulic Piston Corer (HPC) probe. All of these measurements show subsequent temperature disturbances during the decay of the initial frictional heating at penetrations that complicate the determination of backgound temperatures. Simple extrapolation techniques were used to reduce these uncertainties in the temperature and along with determinations of the conductivity structure yield a heat-flow estimate of $78.3 \pm 5.2 \mathrm{~mW} / \mathrm{m}^{2}$. This value is in close agreement with previous determinations obtained from shallow penetration measurements in the near vicinity and is $20 \%$ to $25 \%$ higher than expected from standard lithospheric models. After applying an additional theoretical correction of $10 \%$ for the cooling effect of sedimentation, we estimate that the geothermal flux is 85 to $90 \mathrm{~mW} / \mathrm{m}^{2}$. This suggests that the entire 1-km regional depth anomaly observed in the Labrador Sea may be caused by an unusually thin and hot lithosphere, which was kept from cooling by a widespread zone of hot-spot activity until after spreading ceased between Labrador and Greenland.
\end{abstract}

\section{INTRODUCTION}

The bathymetry, sediment cover, gravity, and magnetic fields of the Labrador Sea have been extensively surveyed (Srivastava et al., 1981). Its history of seafloor spreading is documented by sequences of magnetic reversals that begin at chron 34 ( $84 \mathrm{Ma})$, soon after the initial opening between Greenland and Labrador, and end when active spreading terminated before chron 13 (36 Ma). This pattern is complicated by the existence of a number of both major and minor fracture zones (Fig. 1) and one major reorientation of its spreading center at chron $24(56 \mathrm{Ma})$. The result is a complex and often fragmented set of anomalies that are often difficult to identify uniquely, but that form important constraints to the reconstruction of the entire North Atlantic Ocean (Srivastava and Tapscott, 1986).

Before the dating of basal sediments at Ocean Drilling Program (ODP) Site 647, no independent verification of the ages based on this magnetic anomaly interpretation was available. Given such corroboration (Srivastava and Arthur, this volume), we can now begin to examine other age-related properties of the Labrador Sea with confidence, such as basement depths, subsidence history, and heat flow, in comparison with those of the major ocean basins. In particular, we wish to understand the causes of its substantially elevated topography, initially ascribed by Hyndman (1973) to compositional differences in its lithospheric structure, caused by the existence of hot-spot activity in Davis Strait early in its rifting history. Detailed seismic measurements at Sites 646 and 647 , reported by Srivastava et al. (this volume), indicate that basement depths are, on average, at least $1 \mathrm{~km}$ too shallow for the age of its crust. The lack of any largeamplitude, long-wavelength gravity anomaly within the Labrador Basin indicates that these elevated depths are compensated. Geothermal measurements as well as seismic-refraction observations of crustal and mantle structures can help to constrain the nature of this compensation.

\footnotetext{
${ }^{1}$ Srivastava, S. P., Arthur, M., Clement, B., et al., 1989. Proc. ODP, Sci. Results, 105: College Station, TX (Ocean Drilling Program).

2 Department of Oceanography, Dalhousie University, Halifax, Nova Scotia B3H 4J1, Canada.

3 Graduate School of Oceanography, University of Rhode Island, Narragansett, RI 02882 .

4 Atlantic Geoscience Centre, Geological Survey of Canada, Bedford Institute of Oceanography, Dartmouth, Nova Scotia B2Y 4A2, Canada.
}

Figure 1 shows the heat-flow values that previously were reported for the Labrador Basin. These are limited primarily to the southeastern sector of the Labrador Sea, where six of eight values range from 62 to $69 \mathrm{~mW} / \mathrm{m}^{2}$. Based on these values, standard lithospheric cooling models (e.g., Parsons and Sclater, 1977) yield age estimates of 46 to $57 \mathrm{Ma}$. These values agree closely with the identification of anomalies 21 through 24 (50 to $56 \mathrm{Ma}$ ). Only two previous values in the northwestern sector have been reported (see Fig. 1), and both of these are anomalously low. Pye and Hyndman (1972) suggested that this reduction was caused by the blanketing effect of the thick sediment cover. When they estimated this effect using the model of Von Herzen and Uyeda (1963), they obtained corrected values of 49 and $59 \mathrm{~mW} / \mathrm{m}^{2}$, which agree more closely with the heat flow expected from lithosphere of this age. Recent sedimentation models of Hutchison (1985), however, suggest that these corrections are probably too large.

These normal, or possibly low heat-flow measurements are surprising, considering the anomalously shallow water depths that were observed throughout this basin. This is unlike other examples of hot-spot activity on old lithosphere, which generally show small positive thermal anomalies associated with geoid and topographic swells (Detrick et al., in press). For this reason, surface heat-flow measurements were undertaken during the site surveys for Leg 105, as well as a single borehole measurement at Hole 646A. In this study we detail the analysis of the downhole measurements at Hole $646 \mathrm{~A}$ and compare the final heat-flow determination to the nearby surface penetrations. Both of these independent observations yield mean values of 78 to $79 \mathrm{~mW} /$ $\mathrm{m}^{2}$, which is roughly $20 \%$ to $25 \%$ higher than expected for a normal lithosphere having an age of $55 \mathrm{Ma}$. Thus, as we estimate below, approximately one-half of the 900 to $1200 \mathrm{~m}$ depth anomaly at this site may be linked to an anomalously thin lithosphere, without requiring any unusual composition. The remaining half of the depth anomaly requires additional effects, such as thicker crust or an elevated asthenospheric temperature.

\section{METHODS AND DATA ANALYSIS}

Temperatures were measured at Hole 646A using the Woods Hole HPC probe (Horai and Von Herzen, 1985) at three depths: Core 105$646 \mathrm{~A}-4 \mathrm{H}$ at $35.8 \mathrm{mbsf}$; Core $105-646 \mathrm{~A}-7 \mathrm{H}$ at $64.8 \mathrm{mbsf}$; and Core 105$646 \mathrm{~A}-10 \mathrm{H}$ at $93.8 \mathrm{mbsf}$. Temperature data for each run were recorded every $15 \mathrm{~s}$ and are shown in Figure 2, beginning at the initial penetration of the HPC and ending when the core was pulled back about $600 \mathrm{~s}$ later. 


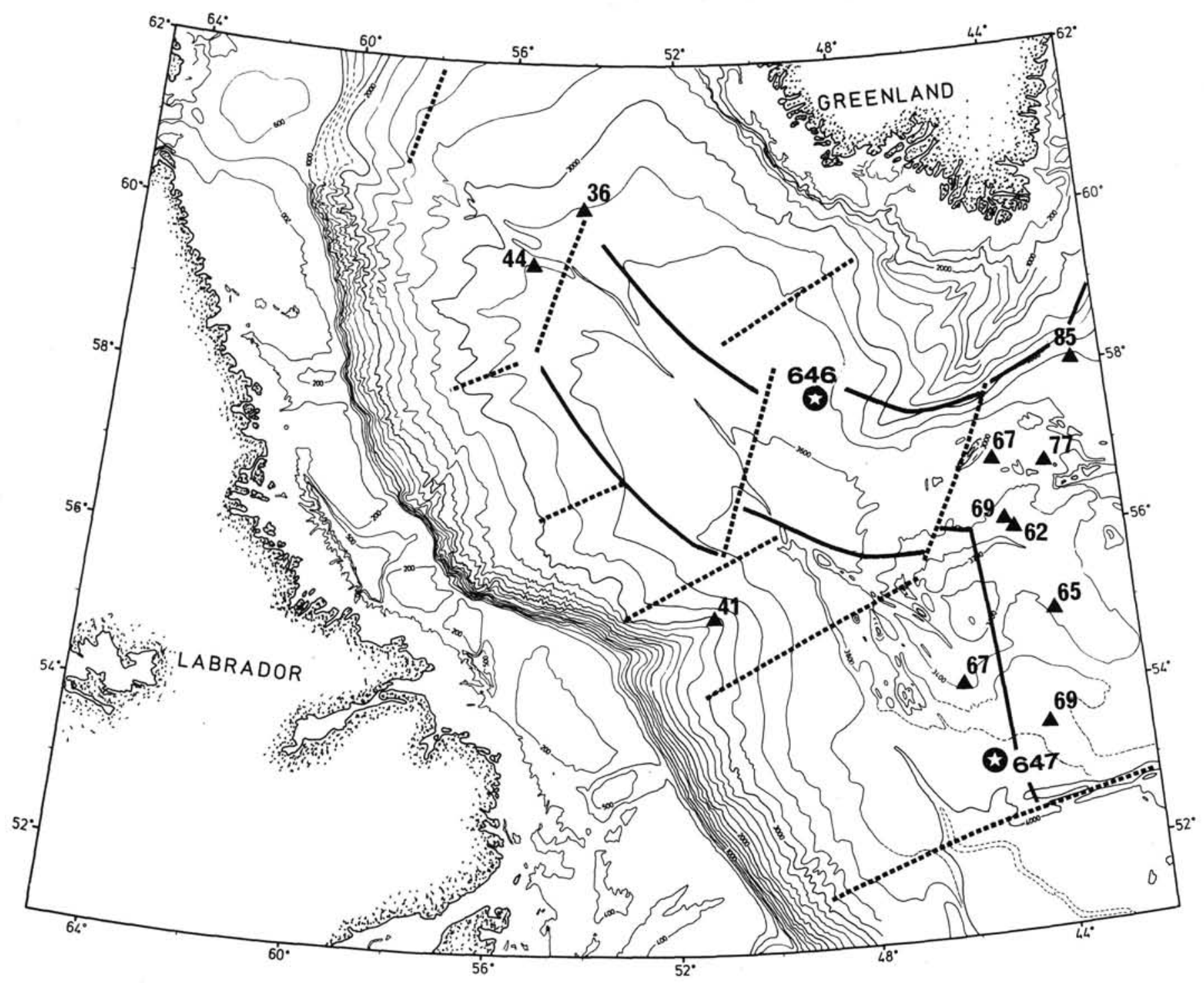

Figure 1. Map of Labrador Sea showing seafloor topography (contours every $200 \mathrm{~m}$; (Canadian Hydrogeographic Service, 1978) and the location of Sites 646 and 647 (stars). Prevous abyssal heat-flow observations (triangles) are given with values in $\mathrm{mW} / \mathrm{m}^{2}$, along with the locations of magnetic anomaly 24 (solid lines) and fracture zones (dashed lines), as compiled by Srivastava and Tapscott (1986) and Louden and Wright (in press).

Each curve shows the primary temperature decay following penetration, but also a number of subsequent disturbances. Some of these, such as at $195 \mathrm{~s}$ for Core $105-646 \mathrm{~A}-4 \mathrm{H}$ and $315 \mathrm{~s}$ for Core $105-646 \mathrm{~A}-10 \mathrm{H}$, may be caused by sudden motions of the corer, which produce additional heat pulses and thermal decays. Other disturbances, such as at $370 \mathrm{~s}$ for Core $105-646 \mathrm{~A}-4 \mathrm{H}$; at $180 \mathrm{~s}$ and 400 to $490 \mathrm{~s}$ for Core $105-646 \mathrm{~A}-7 \mathrm{H}$; and 100 to $130 \mathrm{~s}$ for Core $105-646 \mathrm{~A}-10 \mathrm{H}$, are of less clear origin.

These disturbed-temperature decay histories complicate the determinations of background temperatures at each core depth. The initial estimate of geothermal gradient from these data, $74 \mathrm{mK} / \mathrm{m}$, was based on unextrapolated final temperature measurements before removal of the probe (Srivastava, Arthur, et al., 1987). Considerable uncertainty exists in this value, however, because when linearly extrapolated to the seafloor, it predicts a bottom-water temperature of $2.77^{\circ} \mathrm{C}$, which is considerably higher than those that were observed using the HPC probe during its lowering and retrieval $\left(1.72-1.82^{\circ} \mathrm{C}\right)$. In addition, it is clear that temperatures for Core 105-646A-10H were not stabilized (Fig. 2) and if extrapolated further could yield a much lower value. In this case, the temperature gradient at this site may not be linear, but may possibly show a decrease with depth.

To better constrain the heat-flow estimate at this site, we must reconsider the extrapolation of the temperature decays for all cores, including the effects of multiple disturbances. To do this, we seek a function, $F(t)$, so that,

$$
T(t)=T_{\mathrm{s}}+T_{\mathrm{o}} F\left(t-t_{\mathrm{o}}\right),
$$

where $F(0)=1$ and $F(\infty)=0, T_{\mathrm{s}}$ is the undisturbed temperature of the sediment, and $T_{\mathrm{o}}$ is the initial temperature increase caused by the diturbance at $t=t_{\mathrm{o}}$. For cylindrical probes, $F(t)$ is calculated as a series of Bessel functions (Bullard, 1954), with a rate of temperature decay depending primarily on the thermal time constant $\tau, \tau=\kappa_{\mathrm{s}} t / a^{2}$, where $a$ is the probe's radius and $\kappa_{\mathrm{s}}$ is the thermal diffusivity of the sediment. For long times or small diameter probes, this function approaches the asymptotic form given by Blackwell (1954),

$$
F\left(t-t_{\alpha}\right)=Q /\left[4 \kappa_{\mathrm{s}}\left(\mathrm{t}-\mathrm{t}_{\mathrm{o}}\right)\right],
$$

where $\kappa_{\mathrm{s}}$ is the thermal conductivity of the sediment and $Q$ is the total output of frictional heat. For the WHOI HPC probe, which is in the shape of an annular coring shoe surrounded both inside and outside by sediment, the decay function has been approximated by the radial cooling of a pipe raised to an initially uniform temperature, $T_{o}$ (Horai and Von Herzen, 1985; Morin and Von Herzen, 1986). These solutions yield 

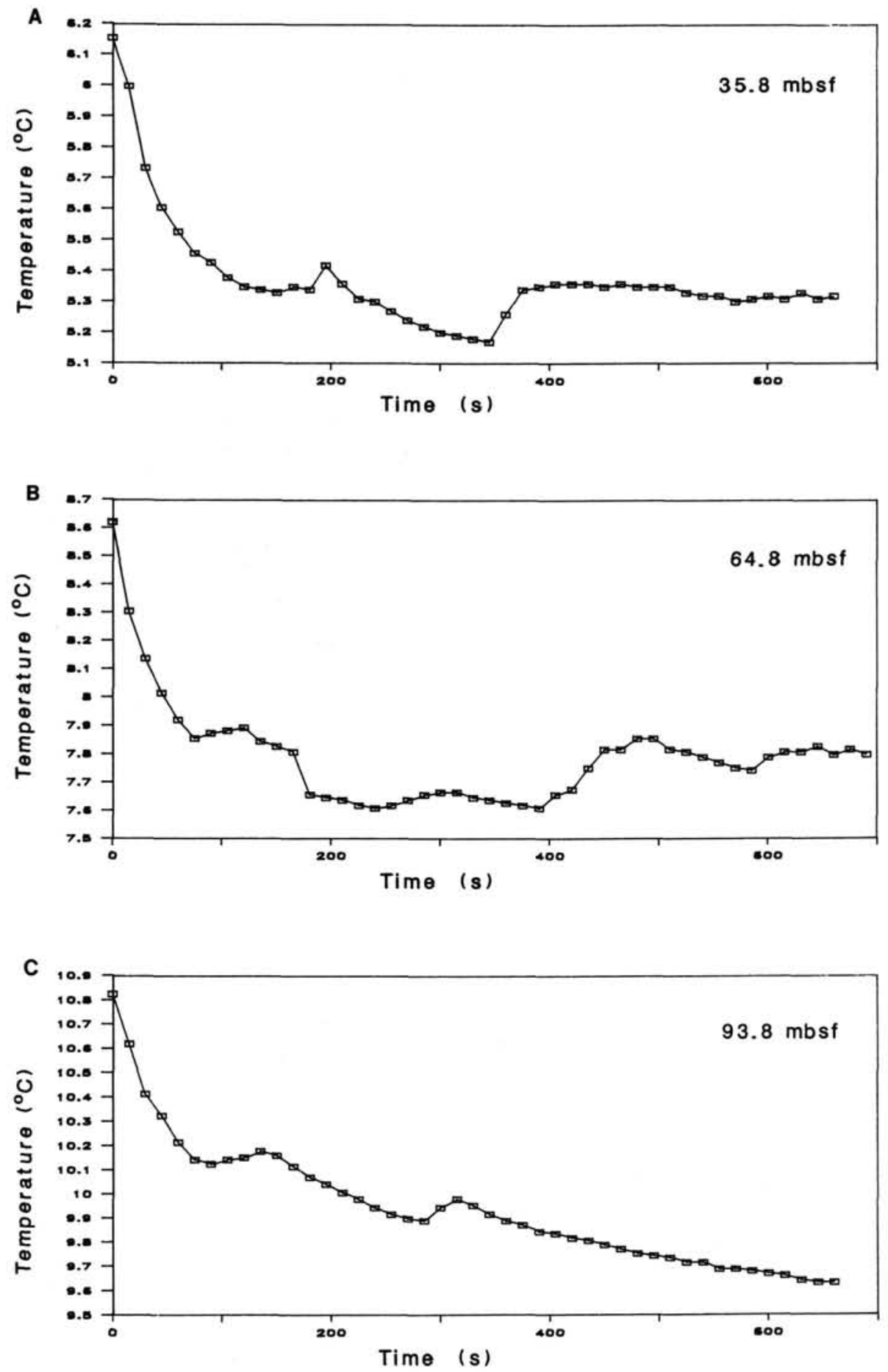

Figure 2. Temperature decay vs. time since penetration for three cores from Site 646A. A. 105$646 \mathrm{~A}-4 \mathrm{H}$; B. 105-646A-7H; and C. 105-646A-10H.

a much slower rate of temperature decay, and lower values of the sediment temperature $T_{s}$, than would extrapolations based on Equation 2 .

Unfortunately, the application of this method requires fitting a nonlinear function to the observed temperature decay. This becomes uncertain when there are multiple secondary heating events that disturb the long-term record. Because of these uncertainties, we have chosen the simplest possible decay function, $1 /\left(t-t_{o}\right)$, with which to attempt determinations of $T_{s}$ from the data in Figure 2. These are shown in Figures 3 through 5 for times following the initial five points $(60 \mathrm{~s})$, during which we would not expect to see linear decays.
For Core 105-646A-4H (Fig. 3A), we see a uniform decrease in the initial temperature pulse from 75 to $150 \mathrm{~s}$. The subsequent heat pulse at $195 \mathrm{~s}$ (Fig. 3B) and its subsequent decay is clearly apparent. A linear fit to the initial decay yields a background temperature, $T_{s}$, of $5.18^{\circ} \mathrm{C}$. To consider the uncertainty in this value caused by the subsequent disturbance, we first calculate a residual temperature in which the continuation of the initial decay has been subtracted. The residual is then plotted as a function of $1 /\left(t-t_{o}\right)$, where $t_{o}=195 \mathrm{~s}$. This also yields a linear curve between 255 and $345 \mathrm{~s}$, which intercepts the origin at $-0.12^{\circ} \mathrm{C}$. A subsequent disturbance of approximately +0.09 to $0.12^{\circ} \mathrm{C}$ exists after 


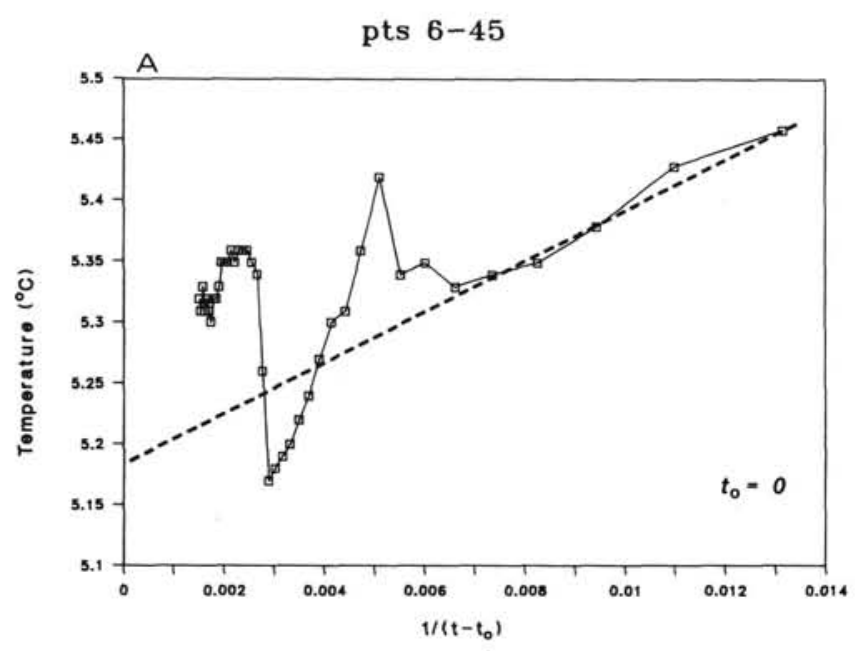

pts $16-45$

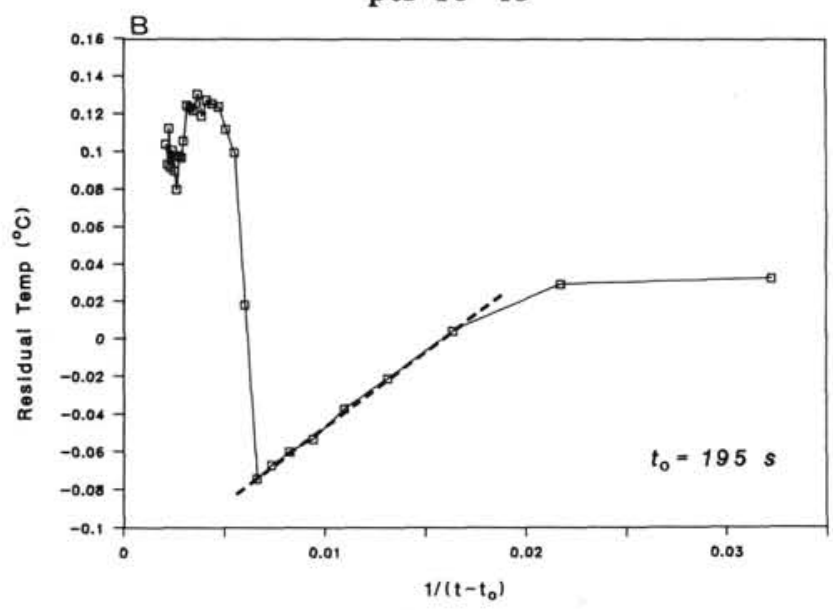

Figure 3. Temperature decay vs. $1 /\left(t-t_{o}\right)$ for Core $105-646 \mathrm{~A}-4 \mathrm{H}$, plotted with respect to (A) the initial decay $\left(t_{o}=0\right)$; and (B) the subsequent disturbance at $t_{o}=195 \mathrm{~s}$. Residual temperatures in (B) are calculated relative to the linear extrapolation of the initial temperature decay in A. Values for each linear extrapolation are given in Table 1.

this, but does define a smooth curve. Thus, we estimate that $T_{s}$ falls somewhere between the extreme values of 5.06 and $5.30^{\circ} \mathrm{C}$ (Table 1).

Data for Cores $105-646 \mathrm{~A}-7 \mathrm{H}$ and $105-646 \mathrm{~A}-10 \mathrm{H}$ are similarly analyzed in Figures 4 and 5. Core 105-646A-7H shows the most complex pattern, with subsequent disturbances at 300 and $480 \mathrm{~s}$. In addition, its initial decay shows a step down of $-0.13^{\circ} \mathrm{C}$ at $180 \mathrm{~s}$. This does not appear to alter the slope of the temperature decay, but rather restores its level to that between 0 and $75 \mathrm{~s}$ (see Fig. 2). Our estimate for $T_{s}$ is $7.46^{\circ} \mathrm{C}$ from the initial decay, with subsequent corrections of 0.04 and $0.13^{\circ} \mathrm{C}$, as summarized in Table 1 .

Core $105-646 \mathrm{~A}-10 \mathrm{H}$ shows a much simpler decay pattern with only one well-defined subsequent disturbance at $t_{o}=315 \mathrm{~s}$. Once again, as with Core $105-646 \mathrm{~A}-7 \mathrm{H}$, the initial temperatures slowly increase between 90 and $135 \mathrm{~s}$. In this case, however, there is no subsequent step down, so we can only assume that the slope of the linear decay between 150 and $285 \mathrm{~s}$ has not been altered by secondary heating. The initial estimate for $t_{s}$ is $9.57^{\circ} \mathrm{C}$, based on this extrapolation. A subsequent pulse at $t_{o}=315 \mathrm{~s}$ shows an additional decay; but when corrected for the continuation of the earlier decay and plotted with respect to its new origin time, this residual effect $\left(-0.11^{\circ} \mathrm{C}\right)$ is much reduced.

Use of our overly simplified extrapolation technique may, however, systematically overestimate the background temperature, $T_{s}$, when compared to the slower rates of decay presented for DSDP Leg 86 by Horai and Von Herzen (1985) and for DSDP Leg 90 by Morin and Von Herzen
(1986). As a simple check, we compared our method to previous data from Leg 90 , Site 587 , at 31.9 mbsf, which has a similarly small $\left(0.7^{\circ}-\right.$ $0.8^{\circ} \mathrm{C}$ ) total temperature loss during the initial $100 \mathrm{~s}$ after penetration. The two different extrapolation methods agree to within $0.15^{\circ} \mathrm{C}$, with our results being the larger. Since the total loss of temperature for all three penetrations at Hole 646A is similar, this offset is probably fairly constant for each extrapolation and thus should cause an even smaller error when determining a temperature gradient.

Another possibility is that subsequent heating events during each core may not be affected by earlier ones if the core has penetrated into a deeper level. In this case, we should extrapolate the actual temperatures, not their residuals, beginning with the new value of $t_{o}$. In fact, such extrapolations yield background temperatures that lie within our previous uncertainties, with the exception of Core $105-646 \mathrm{~A}-7 \mathrm{H}$, which has temperatures $0.1^{\circ} \mathrm{C}$ higher.

\section{RESULTS AND DISCUSSION}

The extrapolated temperature values derived in the previous section are summarized in Table 1. To derive an estimate of the mean heat flow at Hole $646 \mathrm{~A}$, these must be combined with sediment thermal conductivities. In Figure 6 we plot thermal conductivities as a function of depth over the interval of the temperature measurements, as previously reported (Srivastava, Arthur, et al., 1987), and corrected for in-situ conditions using Hyndman et al.'s method (1974). These measurements show a slight increase in conductivity with depth. Therefore, rather than calculate the mean heat flow from the product of the harmonic mean of these values $(0.97 \pm 0.10 \mathrm{~W} / \mathrm{m}-\mathrm{K})$ with the mean temperature gradient, we instead calulated the Bullard depth (Bullard, 1939),

$$
R\left(z_{n}\right)=\sum_{i=0}^{n} \Delta z_{i} / k_{i s}
$$

for the depths, $z_{n}$, of each of the three temperature measurements, where $\Delta z_{i}=z_{i}-z_{i-1}$ and $k_{i s}$ is the conductivity measured at $z_{i}$. Values of $R$ are given in Table 1 and a plot of temperature vs. $R$ is given in Figure 7. A linear, least-squares fit to these points yields a heat flow of $78.3 \pm 3.0 \mathrm{~mW} / \mathrm{m}^{2}$. The seafloor intercept of $2.0 \pm 0.2^{\circ} \mathrm{C}$ given by this method is now in much closer agreement with the range of bottom-water temperatures measured at Hole $646 \mathrm{~A}\left(1.79 \pm 0.04^{\circ} \mathrm{C}\right)$ and nearby locations during a site survey $\left(1.93^{\circ} \pm 0.07^{\circ} \mathrm{C}\right.$; Srivastava et al., this volume; Louden et al., unpubl. data). The fact that these temperatures are $0.2^{\circ} \mathrm{C}$ higher is also consistent with the magnitude of possible systematic errors caused by our extrapolation technique, as previously mentioned.

However, the uncertainty in our heat-flow estimate is probably larger than suggested by the linear fit in Figure 7 . Needleprobe measurements of thermal conductivity have an inherent uncertainty of approximately $5 \%$ (Goldberg, 1981), which is roughly equivalent to the deviation of the conductivity values $(S E= \pm 0.03 \mathrm{~W} / \mathrm{m}-\mathrm{K})$ about an assumed linear trend (Fig. 6). Therefore, we calculated a $95 \%$ confidence interval $( \pm 2 S E)$ of $5.2 \mathrm{~mW} / \mathrm{m}^{2}$ by combining the deviations about assumed linear trends of both conductivity vs. depth and temperature vs. $R$. We assume, with some justification as given previously, that our method of temperature extrapolation has not produced any additional systematic errors.

A heat flow at Hole $646 \mathrm{~A}$ of $78 \mathrm{~mW} / \mathrm{m}^{2}$ is much higher than expected from the previous measurements of Pye and Hyndman (1972) to the northwest, and is more in agreement with the highest of the values just south of Greenland and east of Hole 646A (Fig. 1). Additional heat-flow measurements taken near Site 646 during its site survey (Srivastava et al., this volume; Louden et al., in prep) are located in Figure 8 . The mean of these additional values is $79.3 \pm 3.4 \mathrm{~mW} / \mathrm{m}^{2}$, in close agreement with 

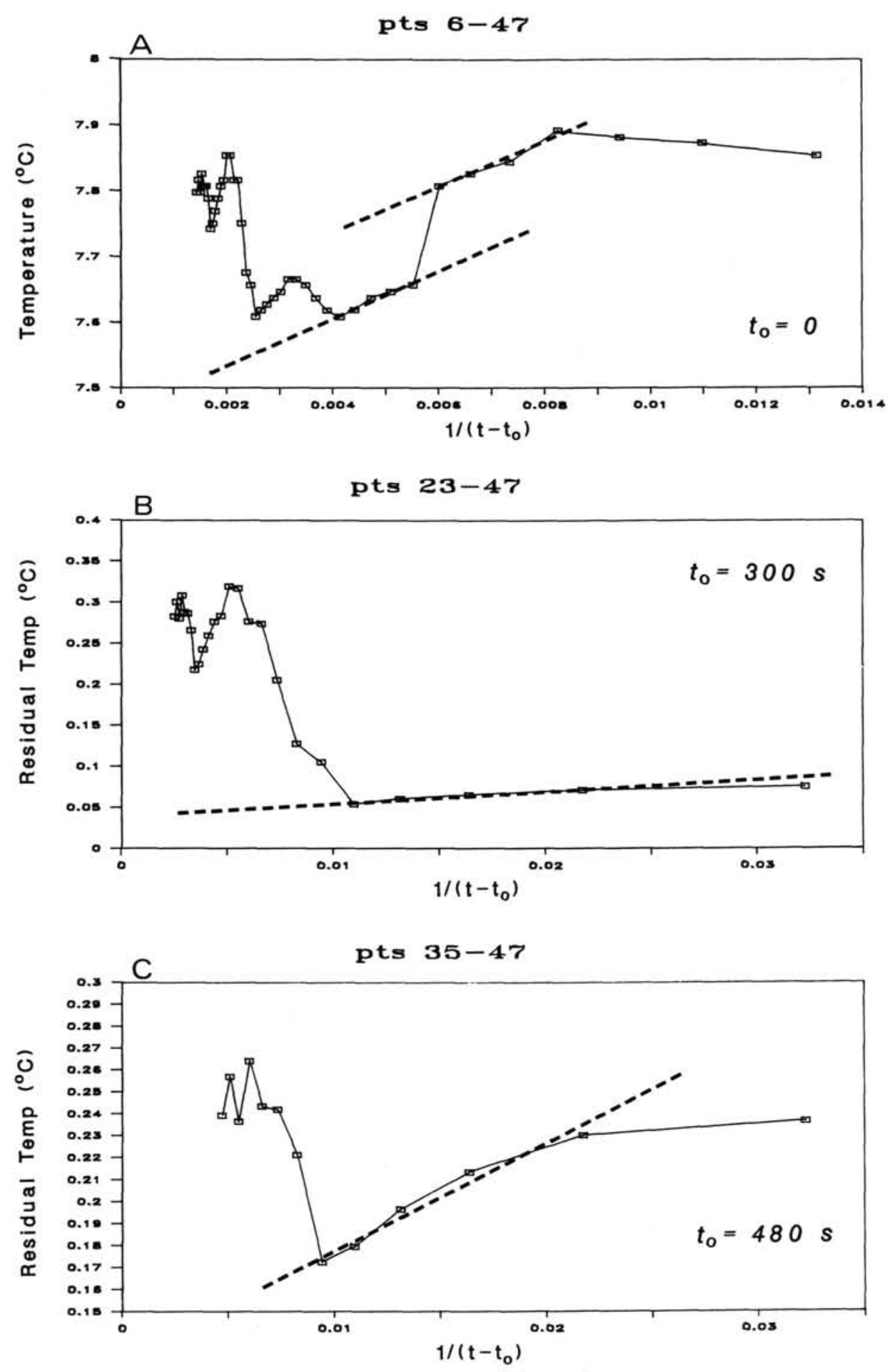

Figure 4. Temperature decay vs. $1 /\left(t-t_{o}\right)$ for Core 105-646A-7H plotted with respect to: (A) the initial decay $\left(t_{o}=0\right)$ and the subsequent disturbances at (B) $t_{o}=300 \mathrm{~s}$, and C. $t_{o}=480 \mathrm{~s}$. Each broken line shows linear extrapolation of initial and subsequent cooling; residual temperatures are calculated relative to each previous decay. Values for each extrapolation are given in Table 1 . The initial decay is offset by $-0.13^{\circ} \mathrm{C}$ at $170 \mathrm{~s}$ but continues with approximately the same slope.

that of Hole 646A. Measurements of in-situ conductivity $(0.91$ $\pm 0.02 \mathrm{~W} / \mathrm{m}-\mathrm{K})$, upon which these heat-flow measurements depend, are also in agreement with near-surface values at Hole 646A (Fig. 6).

Taken as a whole, a heat flow at this site of 78 to $79 \mathrm{~mW} / \mathrm{m}^{2}$ may be well constrained. We estimated the age at this site as 55
Ma, based on the position of anomaly 24 (Fig. 1). Standard oceanic thermal models predict a heat flow of $63 \mathrm{~mW} / \mathrm{m}^{2}$ for lithosphere of this age. Thus, the measured heat flow is approximately $20 \%$ to $25 \%$ higher than expected. When compared with standard oceanic lithospheric cooling models, as shown in Figure 9 , this heat-flow value predicts an age of $35 \mathrm{Ma}$. This thermal age 

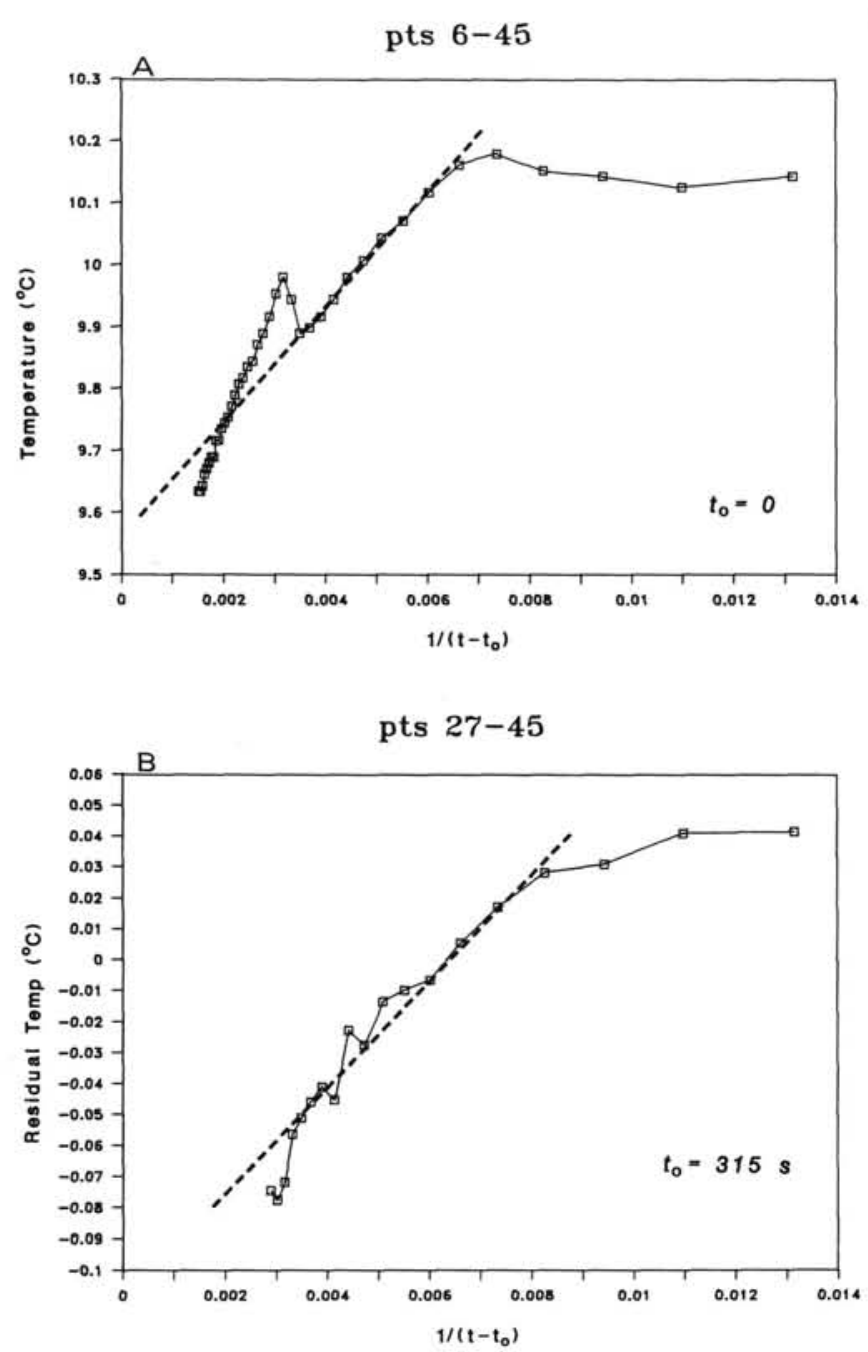

Figure 5. Temperature decay vs. $1 /\left(t-t_{o}\right)$ for Core $105-646 \mathrm{~A}-10 \mathrm{H}$, plotted with respect to: (A) the initial decay $\left(t_{0}=0\right)$; and $(\mathrm{B})$ the subsequent disturbance at $t_{o}=315 \mathrm{~s}$. Each broken line shows linear extrapolation of initial and subsequent cooling trends; residual temperatures in the lower graph are calculated relative to the previous extrapolated decay. Values for each extrapolation are given in Table 1.

Table 1. Summary of extrapolated temperatures at Hole 646A.

\begin{tabular}{ccccccccc}
\hline & & \multicolumn{4}{c}{ Extrapolated temperatures $\left({ }^{\circ} \mathrm{C}\right)$} \\
\cline { 3 - 8 } & & & \multicolumn{4}{c}{ Successive corr. } & \multicolumn{2}{c}{$\begin{array}{c}\text { Final } \\
\text { estimates }\end{array}$} \\
Core & $\begin{array}{c}\text { Depth } \\
(\mathrm{mbsf})\end{array}$ & $\begin{array}{c}\text { Bullard depth } \\
(\mathrm{m} / \mathrm{W} / \mathrm{m}-\mathrm{K})\end{array}$ & $T_{s}$ & $T_{1}$ & $T_{2}$ & $T_{-}$ & $T_{+}$ \\
\hline $4 \mathrm{H}$ & 35.8 & 39.9 & 5.18 & -0.12 & +0.12 & 5.06 & 5.30 \\
$7 \mathrm{H}$ & 64.8 & 68.6 & 7.46 & +0.04 & +0.13 & 7.46 & ${ }^{7} .59 / 7.68$ \\
$10 \mathrm{H}$ & 93.8 & 98.3 & 9.57 & -0.11 & - & 9.46 & 9.58 \\
\hline
\end{tabular}

${ }^{\text {a }}$ See text for explanation.

Note: $Q=78.3 \pm 3.0 \mathrm{~mW} / \mathrm{m}^{2}$.

suggests that the lithosphere might have been kept from cooling by a wide zone of hot-spot-related upwelling, until spreading stopped between Labrador and Greenland sometime before chron 13 (36 Ma). In this scenario, the death of the North Atlantic triple junction might be related to the end or geographical shift in hot-spot activity from the Labrador Sea toward Iceland.
Corrected Conductivity $(W / m / K)$

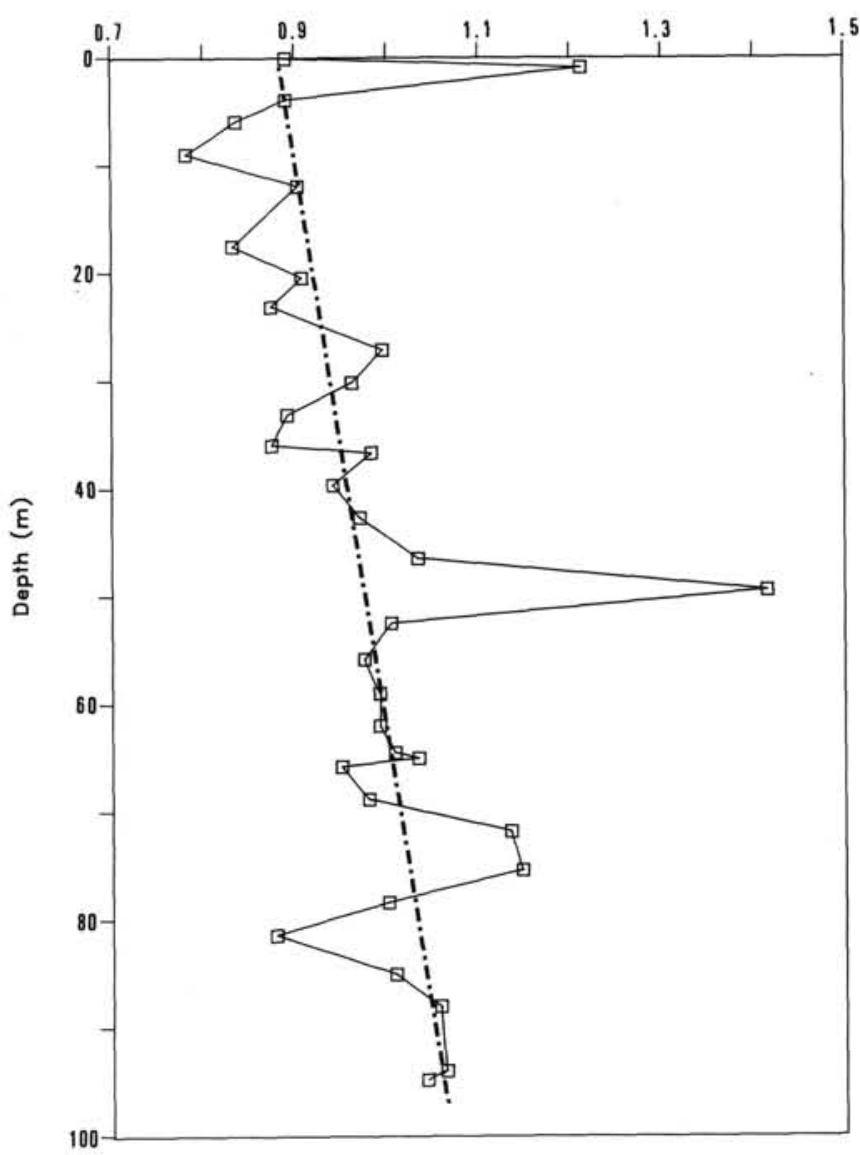

Figure 6. Core conductivities vs. depth, from needle-probe measurements at Hole 646A, corrected for in-situ temperatures and pressures (Hyndman et al., 1974).

Sediment-corrected basement depths in the Labrador Sea also are shallower than expected from the ages of its magnetic anomalies. From normal incidence and wide-angle, seismic-reflection observations (Srivastava et al., this volume), we calculate a sediment-corrected basement depth of 4.1-4.3 km using the methods of either Crough (1983) or LeDouaran and Parsons (1982). These basement depths are consistent with the observed heat flow, as shown in Figure 9, but only for models that assume a zero-age water depth of $2.0 \mathrm{~km}$, which is approximately $500 \mathrm{~m}$ (or $10 \%$ ) shallower than normal.

This excess elevation may be caused by two additional factors:

1. Crust that is thicker or has a mean density of less than normal will create a new isostatic adjustment, according to the following relationships:

$$
\Delta h_{c}=\Delta h_{w}\left[1+\left(\rho_{c}-\rho_{w}\right) /\left(\rho_{m}-\rho_{c}\right)\right] \quad \text { Airy }
$$

or

$$
\Delta \rho_{c} / \rho_{c}=\left(\Delta h_{w} / h_{c}\right) \cdot\left(\rho_{m}-\rho_{w}\right) / \rho_{c} \quad \text { Pratt, }
$$

where $\rho_{w}, \rho_{c}$, and $\rho_{m}$ are the densities of the water $\left(1.0 \mathrm{Mg} / \mathrm{m}^{3}\right)$, crust $\left(2.8 \mathrm{Mg} / \mathrm{m}^{3}\right)$, and mantle $\left(3.3 \mathrm{Mg} / \mathrm{m}^{3}\right)$, respectively, and $h_{c}$ 


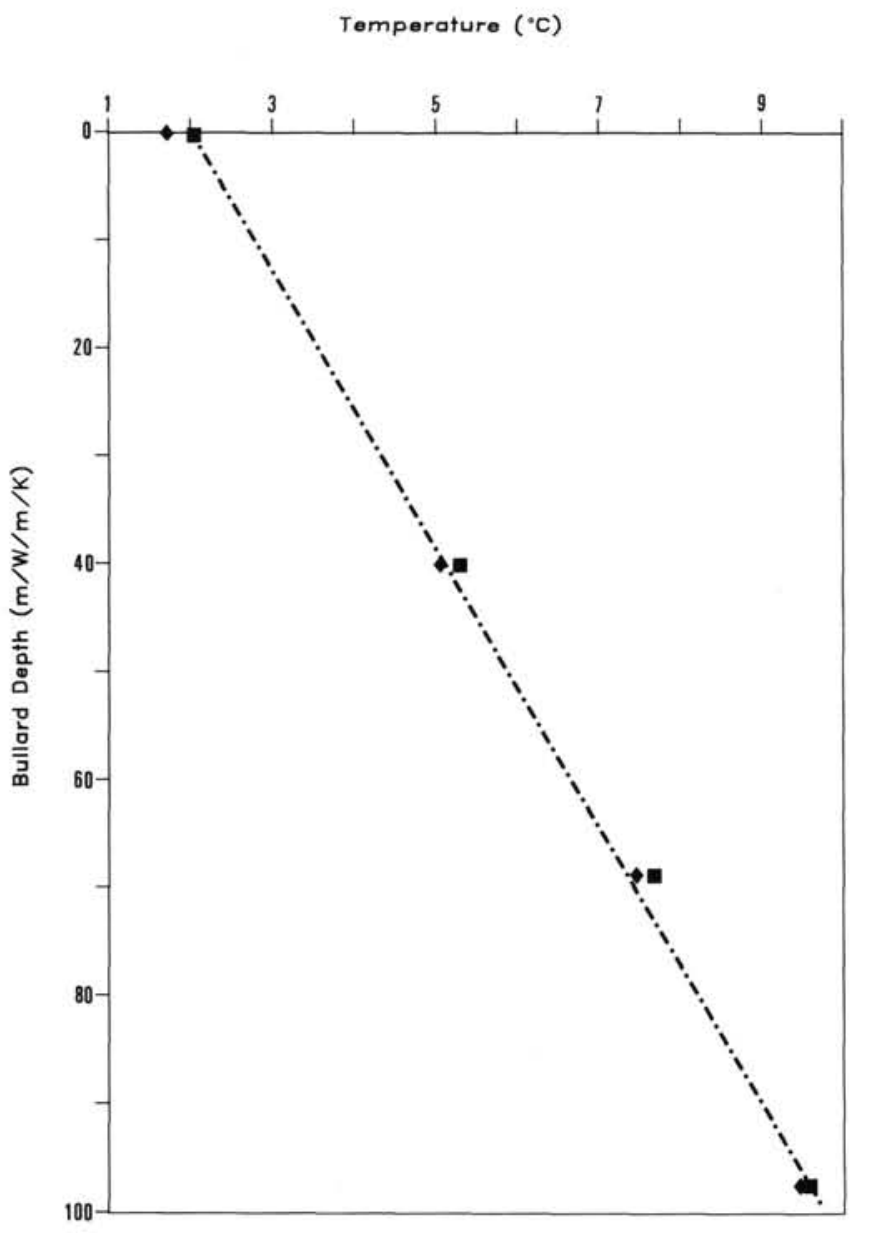

Figure 7. Extraplolated temperatures vs. Bullard depth for Hole 646A. For each temperature determination, squares and diamonds indicate maximum and minimum values, respectively, from Table 1 . Bottom-water temperature extrema bound all values measured during ODP Leg 105 and the Hudson 84-30 site-survey cruise. Heavy broken line is leastsquares fit to the data with a slope of $78.3 \pm 2 \mathrm{~mW} / \mathrm{m}^{2}$.

and $h_{w}$ are the thicknesses of the crust and water layers. Thus, for $\Delta h_{w}=0.5 \mathrm{~km}, \Delta h_{c}=2.3 \mathrm{~km}$ or $\Delta \rho_{c} / \rho_{c}=6 \%$.

2. Higher than normal asthenospheric temperatures will alter the theoretical age-depth relationship in the following manner for the half-space model:

$$
\Delta h_{w}=\Delta T_{m}\left[2 \rho_{m} \alpha /\left(\rho_{m}-\rho_{w}\right)\right] \sqrt{\kappa_{m} \mathrm{t} / \tau},
$$

so

$$
\Delta h_{w} / h_{w}=\Delta T_{m} / T_{m},
$$

where $T_{m}, \kappa_{m}$, and $\alpha$ are the asthenospheric temperature, diffusivity, and volume coefficient of thermal expansion, respectively. Therefore, a relative change in $h_{w}$ of $0.5 / 4.8$ or $10 \%$ can be produced by the same relative change in $T_{m}$, or roughly $130^{\circ} \mathrm{C}$.

In this latter case, the same percentage change should also occur in heat flow; but this is apparently not observed in the actual observations. In fact, our surface heat-flow measurements may possibly have underestimated the geothermal anomaly at depth, because of the effect of thermal blanketing during higher rates of sedimentation. Recent analyses of this process (see Louden and Wright, 1988) have shown that the anomaly is not large for sedimentation rates of less than $50 \mathrm{~m} / \mathrm{m}$.y., particularly

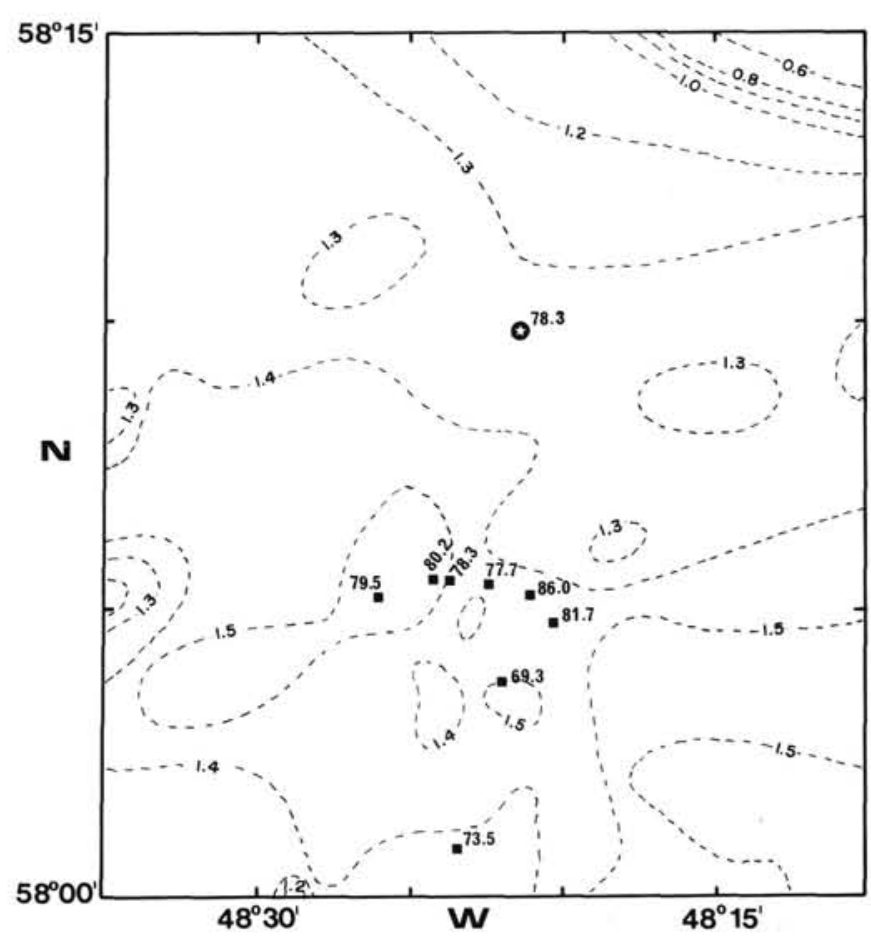

Figure 8. Heat-flow determinations (in $\mathrm{mW} / \mathrm{m}^{2}$ ) from Site 646 (star) and nearby surface penetrations (squares; Louden et al., unpubl. data). Dotted lines are contours of total sediment thickness (in seconds of twoway traveltime), from Srivastava, Arthur, et al., (1987).

when including the compensating process of radiogenic heating within the sediment column. Thus, the large corrections of $35 \%$, determined by Pye and Hyndman (1972) for their heatflow measurements in a region of the northern Labrador Sea having total sediment thicknesses of 1.5 to $2.0 \mathrm{~km}$ and ages of 36 to $56 \mathrm{Ma}$, are not valid if the sedimentation rate has remained constant during the development of the basin.

However, results from Site 646 (Srivastava, Arthur, et al., 1987) show that the recent sedimentation rate has been roughly $90 \mathrm{~m} / \mathrm{m}$.y. during the past 4 to $7 \mathrm{Ma}$, and is probably double that of its earlier ( 7 to $55 \mathrm{Ma}$ ) period. This sudden increase would have produced a reduction of approximately $10 \%$ to $15 \%$ in the heat flow, according to Hutchinson's model (1985), even including the effect of radiogenic heating. In this case, we can explain the depth and heat flow in the Labrador Sea by the same thermal processes: (1) asthenospheric temperatures that are $10 \%$ $\left(130^{\circ} \mathrm{T}\right)$ higher than normal and (2) conductive cooling that does not begin within the entire basin until the termination of spreading at anomaly 13 ( $36 \mathrm{Ma})$.

The possible existence of higher asthenospheric temperatures may also decrease the water depth by creating thicker crust through increased melting and the resultant change in isostatic balance, as described above. This process has been quantified in the melting model of McKenzie and Bickle (1988), and predicts a change in crustal thickness of $8 \mathrm{~km}$ for a change in asthenospheric temperature of $100^{\circ} \mathrm{C}$. This would produce a change in water depth of $1.75 \mathrm{~km}$, according to Equation 4, which is too large. Actually, the more complete calculations of McKenzie and Bickle, which include changes in composition of the crust and complete temperature fields within the mantle, yield a ridge crest depth for this case of $1.1 \mathrm{~km}$ too shallow. Although this result is consistent with the depth anomaly that was observed, there is no evidence from earlier refraction and gravity observations (Van der Linden, 1975; Srivastava et al., 1981) that the 


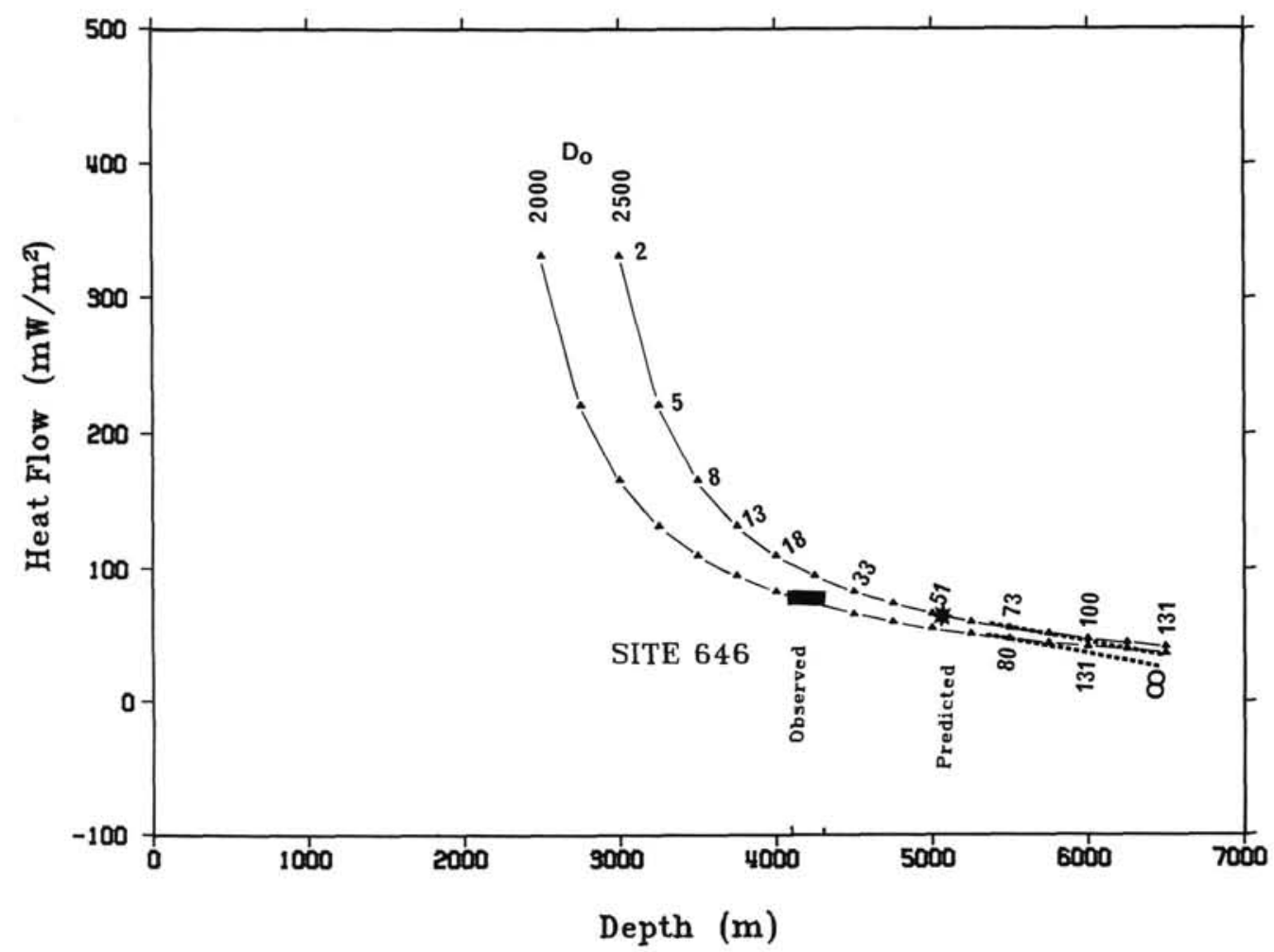

Figure 9. Plot of uncorrected heat flow vs. basement depth observed in the Labrador Sea (solid bar), compared to predictions (star) from theoretical half-space (solid lines) and plate models (broken lines) for differing values of zero-age depth $\left(d_{o}\right)$ or background heat flow, as given by Louden and Wright (in press). Numbers along curves indicate age predictions for each model.

crust of the Labrador Basin in general is as anomalously thick as $17 \mathrm{~km}$. However, at Site 646 some evidence exists from the sonobuoy profile, as shown by Srivastava et al. (this volume), that the crustal structure is unusual in that it contains an anomalously high layer 3 velocity of $7.5 \mathrm{~km} / \mathrm{s}$. Such high lower crustal velocities are observed in regions of thickened crust near continental margins that are thought to be affected by hot-spot activity (White et al., 1987). More refraction data are required from the Labrador Basin to further constrain the relationship between its crustal structure and anomalous depths.

\section{CONCLUSIONS}

Re-analyzing thermal measurements taken at ODP Hole 646A yield a raw mean heat flow of $78.3 \pm 5.2 \mathrm{~mW} / \mathrm{m}^{2}$. Primary limitations to this value are that only three sub-bottom depths were sampled, and that each of these measurements contains a complicated pattern of temperature decay caused by motions of the probe following its initial penetration. However, simple $1 / t$ extrapolations that account for multiple disturbances yield background temperatures that are consistent to within $0.13^{\circ} \mathrm{C}$ at each depth. The use of more complicated extrapolation functions may yield somewhat lower estimates of background temperatures. This may not seriously affect our estimate of the mean heat flow, because of the small and consistent amount of the total frictional temperature decay that was observed at all three depths.

This heat-flow determination is consistent with a mean value of $79.3 \pm 3.4 \mathrm{~mW} / \mathrm{m}^{2}$, which was previously determined from eight near-surface penetrations. Values of near-surface conductivity $(0.89-0.91 \mathrm{~W} / \mathrm{m}-\mathrm{K})$ also agree to within measurement uncertainties of $2 \%$ to $5 \%$.

Clearly, the heat flow at this site in the Labrador Basin is at least $20 \%$ to $25 \%$ higher than was predicted for its age by stan- dard lithospheric thermal models. Correcting for the effects of sedimentation may result in an additional $10 \%$ to $15 \%$ anomaly to yield a corrected heat-flow value of 85 to $90 \mathrm{~mW} / \mathrm{m}^{2}$. In this case, we can relate both the shallow basement and the present heat flow to the same simple thermal model, in which widespread hot-spot activity during the formation of the Labrador Sea created asthenospheric temperatures that are approximately $130^{\circ} \mathrm{T}$ hotter than normal and that kept the lithosphere from cooling until the end of spreading, sometime before chron 13 . This does not require unusual lithospheric composition, as previously suggested by Hyndman (1973).

The unusual nature of the subsidence history suggested by our heat-flow and basement measurements at Hole 646A, as well as by an analysis of sediment deposition at Site 647 (Srivastava and Arthur, this volume), may necessitate the re-examination of previous theoretical models of borehole subsidence data from the Labrador and Greenland margins (Royden and Keen, 1980; Issler and Beaumont, 1988), which have assumed standard oceanic lithospheric parameters.

\section{ACKNOWLEDGMENTS}

This study was supported by NSERC Grants G0870 and A8459 to $K$. Louden. We acknowledge the assistance rendered by the technical staff on board the Resolution for making the heat flow measurements reported here. This is Geological Survey of Canada Contribution No. 43688 .

\section{REFERENCES}

Blackwell, J. H., 1954. A transient flow method for determination of thermal constants of insulating materials in bulk. J. Appl. Phys., 25: 137.

Bullard, E. C., 1939. Heat flow in South Africa. Proc. Roy. Soc. London, Ser. A., 173:474. 
Bullard, E. C., 1954. The flow of heat through the floor of the Atlantic Ocean, Proc. Roy. Soc. London, Ser. A, 222:408.

Canadian Hydrographic Service, 1978. Labrador Sea Bathymetry 1:2000000: Ottawa (Dept. of Fisheries and Oceans).

Crough, S. T., 1983. The correction for sediment loading on the seafloor. J. Geophys. Res., 88:6449-6454.

Detrick, R. S., White, R. S., Courtney, R. C., and Von Herzen, R. P., in press. Heat flow on mid-plate swells. In Wright, J. A., and Louden, K. E. (Eds.), Handbook of Marine Seafloor: Boca Raton (CRC Press).

Goldberg, D. S., 1981. The physical properties of deep ocean sediments from the northern Atlantic: a comparison of in-situ and laboratory methods [M.Sc. thesis], Massachusetts Inst. of Technology.

Horai, K., and Von Herzen, R. P., 1985. Measurement of heat flow on Leg 86 of the Deep Sea Drilling Project. In Heath, G. R., Burkle, L. H., et al., Init. Repts. DSDP, 86: Washington (U.S. Govt. Printing Office), 759.

Hutchison, I., 1985. The effects of sedimentation and compaction on oceanic heat flow. Geophys. J. Roy. Astron. Soc., 82:439.

Hyndman, R. D., 1973. Evolution of the Labrador Sea. Can. J. Earth Sci., 10:637-644.

Hyndman, R. D., Erickson, A. J., and Von Herzen, R. P., 1974. Geothermal measurements on DSDP Leg 26. In Davies, T. A., Luyendyk, B. P., et al., Init. Repts. DSDP, 26: Washington (U.S. Govt. Printing Office), 451.

Issler, D. R., and Beaumont, C., 1988. Thermal and subsidence history of the Labrador and West Greenland continental margins. In Beaumont, C., and Tankard, A. J. (Eds.), Sedimentary Basins and BasinForming Mechanisms. Can. Soc. Pet. Geol. Mem., 12:45-70.

LeDouaran, S., and Parsons, B., 1982. A note on the correction of ocean floor depths for sediment loading. J. Geophys. Res., 87:47154722.

Louden, K. E., and Wright, J. A., in press. Marine heat flow data: a new compilation of observations and brief review of its analysis. In Wright, J. A., and Louden, K. E. (Eds.), Handbook of Seafloor Heat Flow: Boca Raton (CRC Press).
McKenzie, D., and Bickle, M. J., 1988. The volume and composition of melt generated by extension of the lithosphere. J. Petrol., 29:625679.

Morin, R. H., and Von Herzen, R. P., 1986. Geothermal measurements at Deep Sea Drilling Project Site 587. In Kennett, J. P., von de Borch, C. C., et al., Init Repts. DSDP, 90: Washington (U.S. Govt. Printing Office), 1317-1324.

Parsons, B., and Sclater, J. G., 1977. An analysis of the variation of ocean floor bathymetry and heat flow with age. J. Geophys. Res., $82: 803-827$.

Pye, G. D., and Hyndman, R. D., 1972. Heat flow measurements in Baffin Bay and the Labrador Sea. J. Geophys. Res., 77:938-944.

Royden, L., and Keen, C. E., 1980. Rifting processes and thermal evolution of the continental margin of eastern Canada determined from subsidence curves. Earth Planet. Sci. Lett., 51:341-361.

Srivastava, S. P., Arthur, M., et al., Proc. ODP, Init. Repts., 105: College Station, TX (Ocean Drilling Program), 419-674.

Srivastava, S. P., Falconer, R.K.H., and MacLean, B., 1981. Labrador Sea, Davis Strait, Baffin Bay: geology and geophysics-a review. Can. Soc. Pet. Geol. Mem., 7:333-398.

Srivastava, S. P., and Tapscott, C. P., 1986. Plate kinematics of the North Atlantic. In Vogt, P. R., and Tuchlolke, B. E. (Eds.), The Geology of North America, Vol. M, The Western North Atlantic Region: Washington (Geol. Soc. Am.), 379-404.

Van der Linden, W.J.M., 1975. Crustal attenuation and seafloor spreading in the Labrador Sea. Earth Planet. Sci. Lett., 27:409-423.

Von Herzen, R. P., and Uyeda, S., 1963. Heat flow through the eastern Pacific Ocean floor. J. Geophys. Res., 68:4219.

White, R. S., Spence, G. D., Fowler, S. R., McKenzie, D. P., Westbrook, G. K., and Bowen, A. N., 1987. Magmatism at rifted continental margins. Nature, 330:439-444.

Date of initial receipt: 31 March 1988

Date of acceptance: 3 January 1989

Ms 105B-153 